\title{
EXPERIMENTAL STUDIES ON PRESSURE DROP IN A SINUSOIDAL PLATE HEAT EXCHANGER: EFFECT OF CORRUGATION ANGLE
}

\author{
B. Sreedhara Rao ${ }^{1}$, Varun S ${ }^{2}$, MVS Murali Krishna ${ }^{3}$, R C Sastry ${ }^{4}$ \\ ${ }^{1}$ Asst professor, ${ }^{2}$ PG Student, ${ }^{3}$ Professor, Department of Chemical Engineering, CBIT Hyderabad, AP, INDIA \\ ${ }^{4}$ Professor, Department of Chemical Engineering, NIT Warangal, AP, INDIA
}

\begin{abstract}
The corrugated plate heat exchangers are widely used in food and pharmaceutical industries. Sinusoidal plate heat exchangers are one of the types of corrugated plate heat exchanger. Limited research work has been carried out in this type of plate heat exchanger. In the present investigation, experimental studies have been carried out in a sinusoidal corrugated plate heat exchanger with water as the test fluid. The plate heat exchanger is fabricated with two stainless steel sheets having a thickness of $1 \mathrm{~mm}$ forming a test channel with a clearance of $5 \mathrm{~mm}$ and of length $30 \mathrm{~cm} .3$ such plate heat exchangers have been fabricated with corrugation angles of 30, 40 and 50 degrees. It has been observed from the experimental results that the corrugation angle is mainly affecting the pressure drop and the friction factor. As the corrugation angle is increases, the pressure drop of the fluid is found to increase, which results in decrease in friction factor. These observations have been discussed in the paper.
\end{abstract}

Keywords: sinusoidal plate heat exchanger, corrugation angle, pressure drop, and friction factor

\section{INTRODUCTION}

Heat exchangers form crucial components in any chemical industry. Heat exchangers have undergone a lot of evolution in due course of time. The latest in this being the development of compact heat exchangers, which have a surface area to volume ratio more than $700 \mathrm{~m}^{2} / \mathrm{m}^{3}$. In compact heat exchangers, a lot of research has been focused on plate heat exchangers. Plate heat exchangers are highly attractive for use because of its high heat transfer efficiency, ease of handling, highly portable nature and ease with which it can be scaled up. A large number of types of plate heat exchangers exist depending on the type of corrugation present on the plate. Some commonly used corrugations include chevron type and the sinusoidal plates that are being discussed in detail in this paper.

The enhancement of heat transfer in plate heat exchangers can be attributed to highly complex flow phenomena existing in between the plates. It is totally dependent on the corrugation pattern used. These corrugations introduce highly turbulent flow regime even at low Reynolds number.

\section{LITERATURE REVIEW}

Nema et al [1] have carried out similar work involving the heat transfer and pressure drop studies on a sinusoidal plate heat exchanger having a three channel arrangement. It involved study for air-water -system in the Reynolds number range 750-3200 for water and 16900-68000 for air. G. Iulian et al [4] conducted exhaustive experimental studies on a chevron type plate heat exchanger, which involved the determination of nusselt number $(\mathrm{Nu})$, friction factor (f) for various flow conditions. They concluded thst the flow was essentially non uniform and moved along the edges. Heggs et al [2] suggested that a pure laminar flow does not exist in a Reynolds number range of 150-11500 and supported it by studying the heat transfer coefficients experimentally. Liombas et al [3] studied the gas-liquid two phase flow in a wide range of Reynolds number and they concluded from the experiments that flow exhibits basics of turbulent flow for a very low value of Reynolds number like 400 . Extensive mass transfer coefficients measurements were done by Goldstein et al [5] for an Reynolds number range of 150-2000. Lin et al [6] also investigated heat transfer between air-water system in a one side corrugated and one side flat system.

\section{EXPERIMENTAL}

\subsection{Experimental Setup}

The experiments have been conducted on a custom manufactured plate heat exchanger unit shown in Fig 1. The setup consists of a test box, test fluid tank, test fluid collection tank and hot water tank. Each test box consists of three sinusoidal corrugated plates welded together to form a horizontal channel. The sinusoidal plate heat exchanger shown in Fig -2 has the dimensions shown in Table-1, three test boxes of having three different corrugation angles of 30,40 and 50 are considered here. A manometer has been fitted across the test length to measure the pressure drop in the lower test fluid channel. The flow through these two channels is controlled using rotameters. The flow pattern adopted is countercurrent manner. 


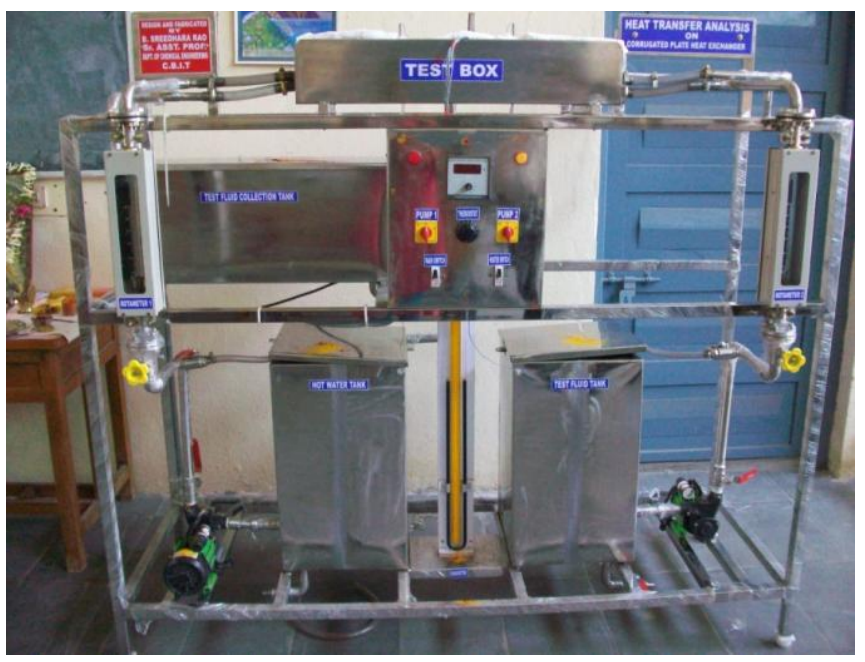

Fig -1: Plate heat exchanger setup.

Table -1: Dimensions of the plate heat exchanger test box

\begin{tabular}{|l|l|}
\hline Parameter & Dimensions \\
\hline Length & $0.30 \mathrm{~m}$ \\
\hline Width & $0.1 \mathrm{~m}$ \\
\hline $\begin{array}{l}\text { Test fluid channel } \\
\text { spacing }\end{array}$ & $0.05 \mathrm{~m}$ \\
\hline Corrugation angles & 30,40 and 50 degrees \\
\hline
\end{tabular}

\subsection{Materials}

The test fluid considered here is water. $\mathrm{CCl} 4$ is used as the manometric fluid. The density and viscosity of all the materials are experimentally determined.

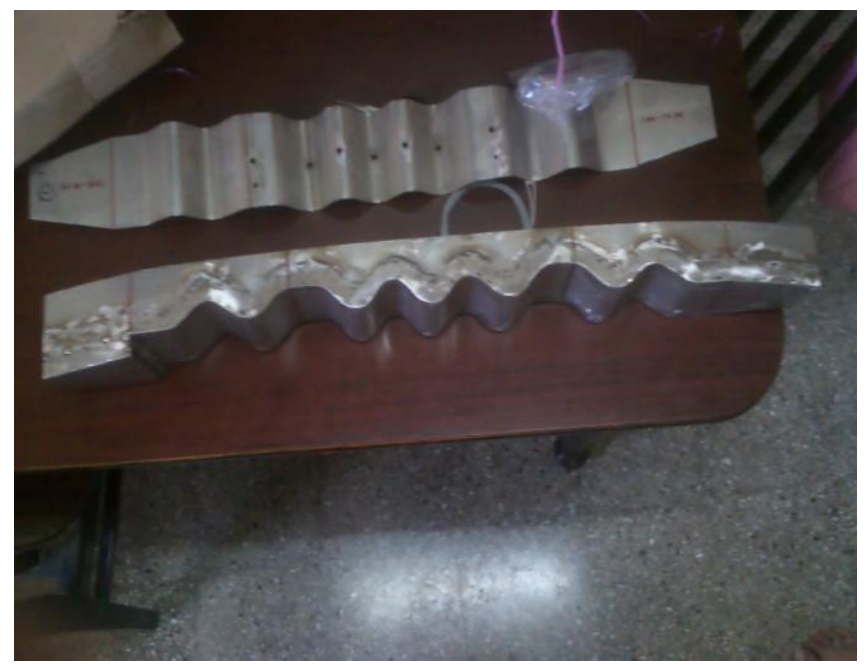

Fig -2: Sinusoidal test section

\subsection{Experimental Procedure}

Once the test fluid is loaded in the test fluid tank, the flow is started through the channel. The flow rate is started at a lower flow rate. The test fluid flow rate is varied from 0.5 to $6 \mathrm{lpm}$ with a step size of $0.25 \mathrm{lpm}$. Once the pressure reading shown by the manometer becomes stable for a given flow rate, the pressure drop readings are noted down and process is repeated for all flow rates. The same experimental procedure is followed for all 3 test channels.

\section{RESULTS AND DISCUSSIONS}

The corrugation angle forms a critical parameter in the study of plate heat exchangers. It is defined in various manners by different researchers. The corrugation angle for the plate heat exchanger is considered with respect to the horizontal as shown in Fig-3.

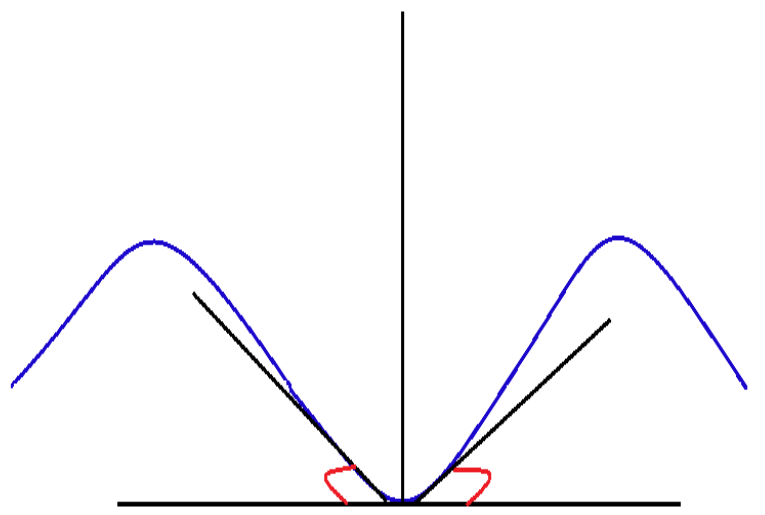

Fig -3: Corrugation angle taken for the sinusoidal plates

The analysis involves the calculation of the Reynolds number for the flow in test fluid channel using the equation.

$$
\operatorname{Re}=\rho v D_{H} / \mu
$$

Pressure drop values for each flow rate are calculated using the pressure readings obtained from the manometer.

$$
\Delta P=H \Delta \rho g
$$

Friction factor can be calculated making use of the flow velocity and the pressure drop for each flow rate.

$$
f=\Delta P /\left(\mathrm{L} / \mathrm{D}_{\mathrm{H}}\right)\left(\mathrm{G}^{*} \mathrm{G} / 2 \rho \mathrm{g}_{\mathrm{c}}\right)
$$

In detailed analysis, the variation of both $\Delta \mathrm{P}$ vs $\mathrm{Re}$ and $\mathrm{f}$ vs $\mathrm{Re}$ for different corrugation angles are studied. 


\subsection{Pressure Drop}

For 30 degree corrugation angle, it can be observed from Fig4 that as the Reynolds number of the flow increases, the pressure drop across the test section also increases. The increase observed is almost linear.

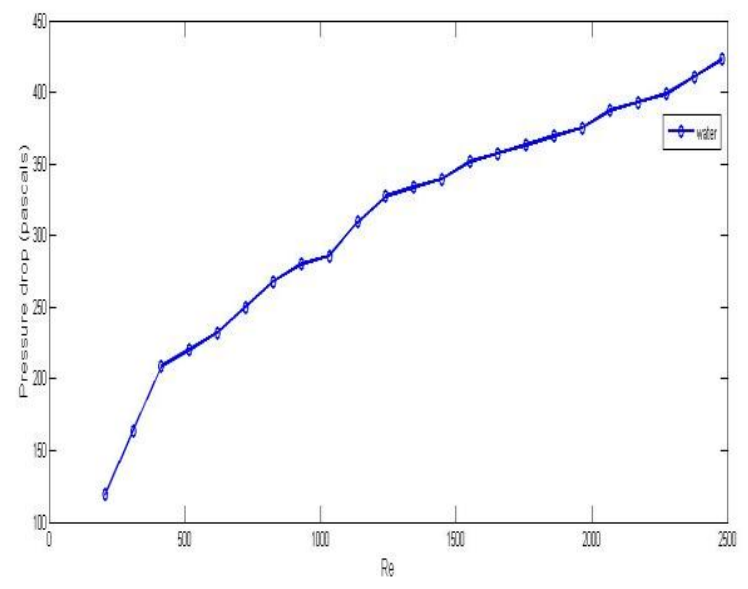

Fig -4: variation in pressure drop with Reynolds number for 30 degree corrugations

For 40 degree corrugation angle, it can be observed from Fig-5 that as the Reynolds number of the flow increases, the pressure drop across the test section also increases. The increase observed is almost linear.

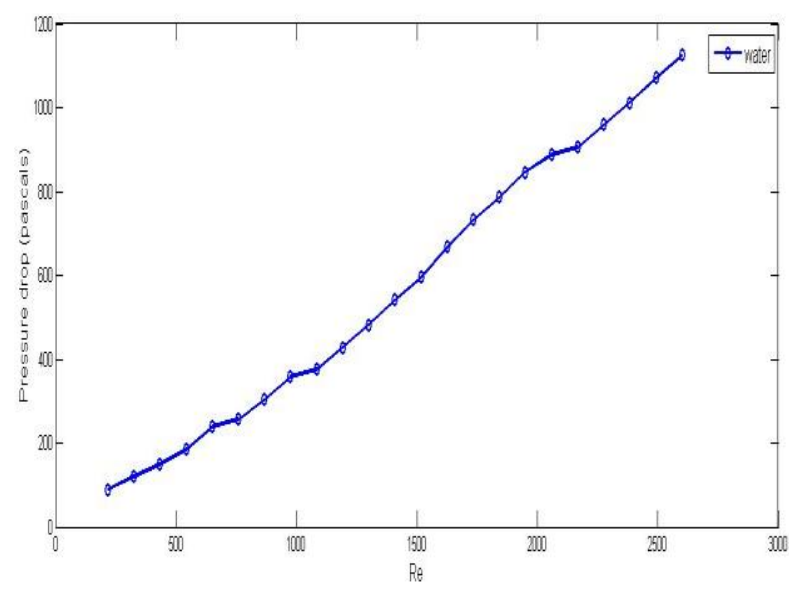

Fig -5: variation in pressure drop with Reynolds number for 40 degree corrugations

For 50 degree corrugation angle, it can be observed from Fig-6 that as the Reynolds number of the flow increases, the pressure drop across the test section also increases. The increase observed is almost linear.

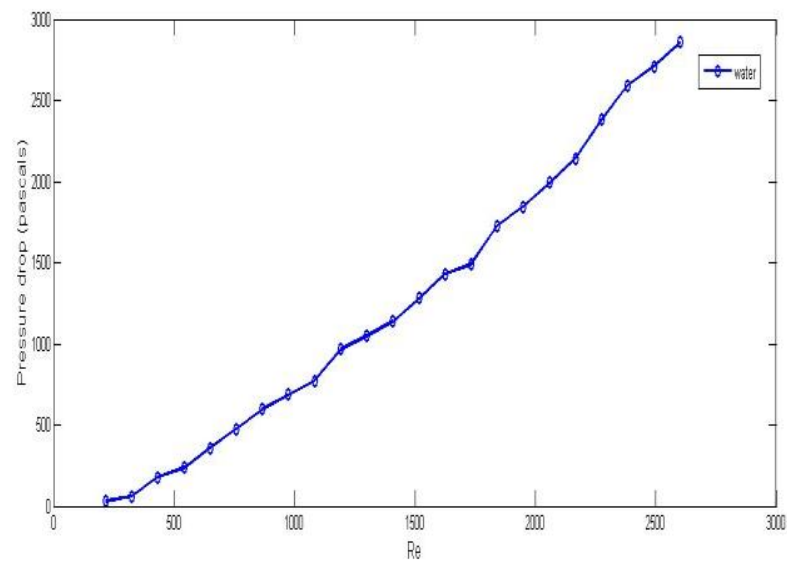

Fig -6: variation in pressure drop with Reynolds number for 50 degree corrugations

When all three corrugation angle are considered together (Fig7), it can be seen that the minimum pressure drop is given by the 30 degree corrugated channel and the maximum pressure is given by 50 degree corrugated test channel. This observation stands valid in the entire range of experimental study. The minimum value of pressure drop obtained is 250 pascals and the maximum obtained is 2800 pascals. So based on this observation, it can be said that as the corrugation angle increases, the pressure drop offered by the test channel also increases.

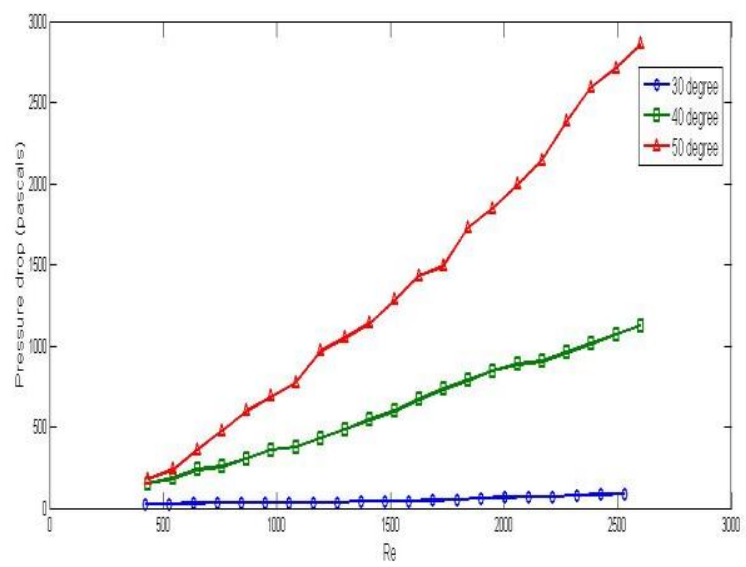

Fig -7: Comparison of pressure drop for all three corrugation angles.

\subsection{Friction Factor}

Theoretically as pressure drop for a flow increases, it results in decrease in the friction factor values. For 30 degree corrugation angle, it can be observed from Fig- 8 that as the Reynolds number of the flow increases, the friction factor across the test section also decreases. The decrease observed is almost linear on a logarithmic scale. 


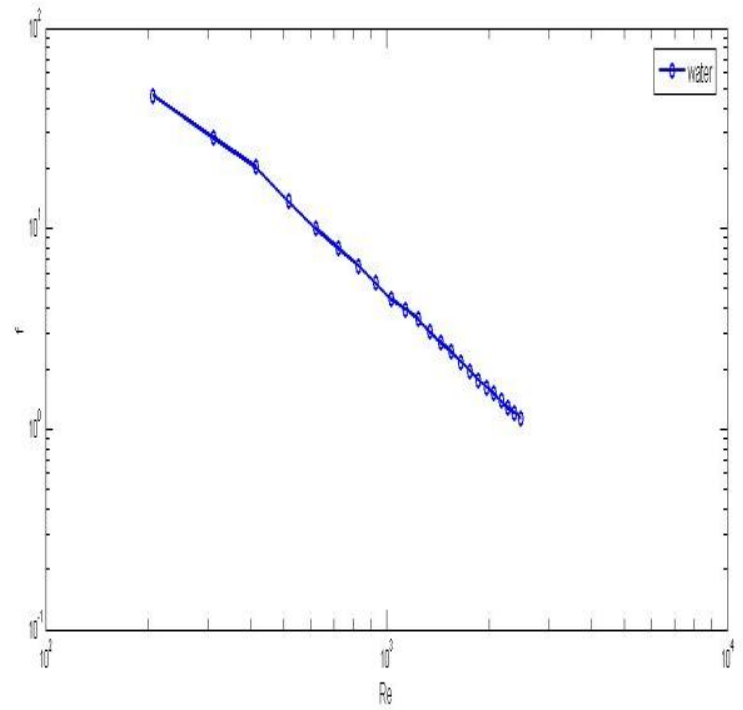

Fig -8: variation in friction factor with Reynolds number for 30 degree corrugations

For 30 degree corrugation angle, it can be observed from Fig-9 that as the Reynolds number of the flow increases, the friction factor across the test section also decreases. The decrease observed is almost linear on a logarithmic scale.

For 30 degree corrugation angle, it can be observed from Fig10 that as the Reynolds number of the flow increases, the friction factor across the test section also decreases. The decrease observed is almost linear on a logarithmic scale.

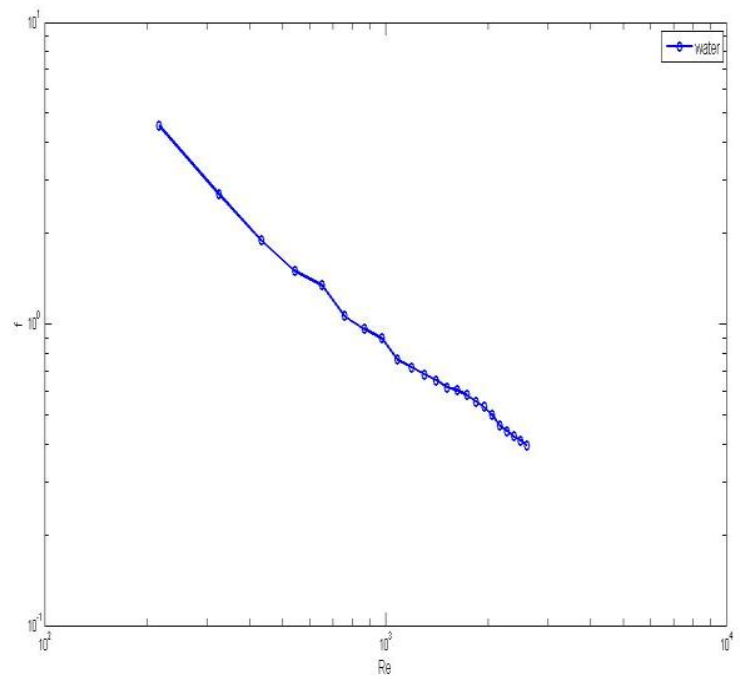

Fig -9: variation in friction factor with Reynolds number for 40 degree corrugations

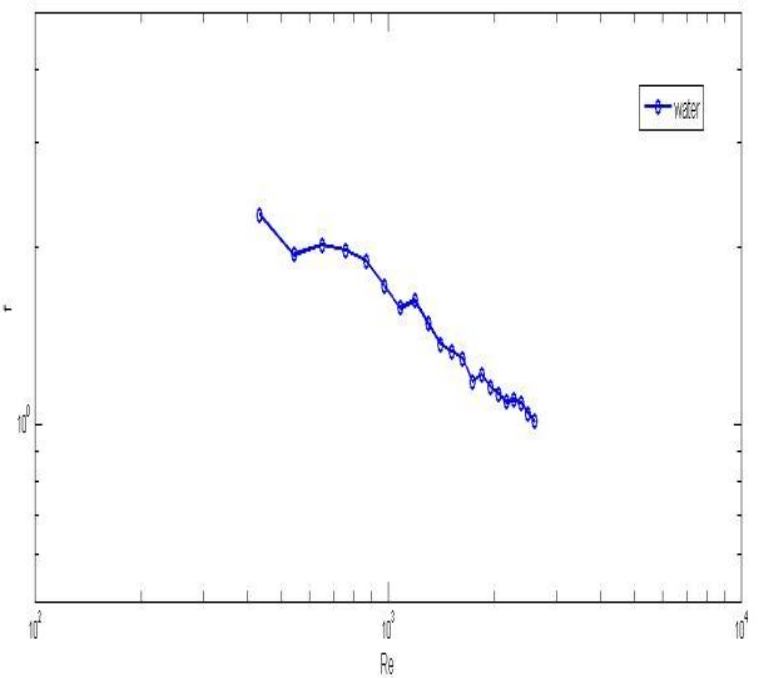

Fig -10: variation in friction factor with Reynolds number for 50 degree corrugations

When all three corrugation angle are considered together (Fig11), it can be seen that the minimum friction factor is given by the 30 degree corrugated channel and the maximum friction factor is given by 50 degree corrugated test channel. This observation stands valid in the entire range of experimental study. The minimum value of friction factor obtained is 0.03 and the maximum obtained is 2.5. So based on this observation, it can be said that as the corrugation angle increases, the pressure drop offered by the test channel increases and it results in the decrease in friction factor values.

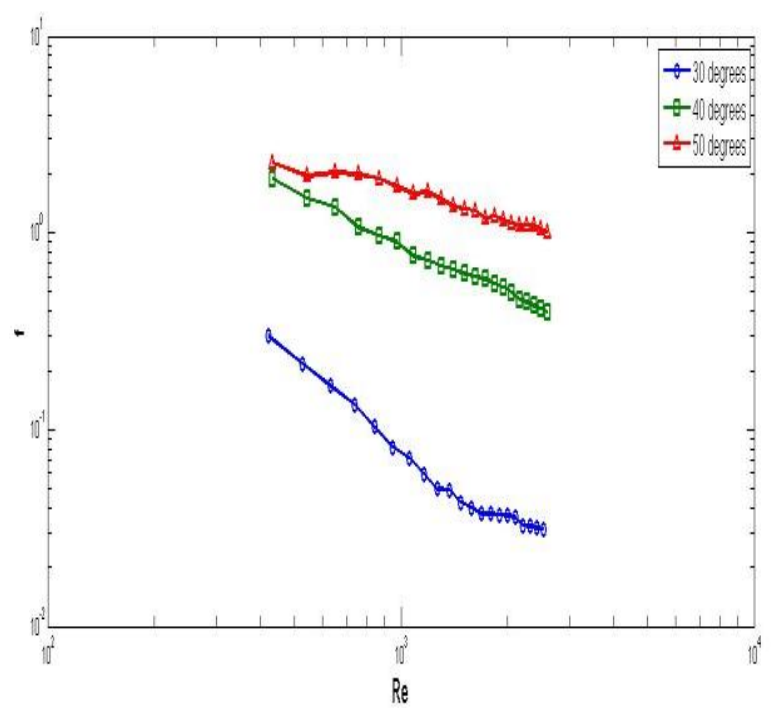

Fig -11: Comparison of friction factor for all three corrugation angles. 


\section{CONCLUSIONS}

So based on this experimental study it can be said that corrugation angle has a prominent effect on both pressure drop and friction factor. As the corrugation angle increases, pressure drop offered by the channel increases and the friction factor deceases. The increase in pressure drop can be attributed to increase in turbulence occurring in the channel. As the corrugation angle increases, the channel becomes sharper and induces turbulence even at a low flow rate.

\section{REFERENCES}

[1]. V.K. Nema, Shive Dayal Pandey,(2011), Experimental investigation of heat transfer and friction factor in a corrugated plate heat exchanger, International Journal Of

Energy And Environment, 2(2):287-296.

[2]. Heggs, P.J., Sandham, P., Hallam, R.A., Walton, C.,( 1997), Local transfer coefficients in corrugated plate heat exchangers channels, Trans IChemE, Part A, Chem Eng Res Des, 75(A7): 641-645.

[3]. Lioumbas, I.S., Mouza, A.A. and Paras, S.V.,( 2002), Local velocities inside the gas phase in counter current twophase flow in a narrow vertical channel, Trans IChemE, Part A, Chem Eng Res Des, 80(6):667-673.

[4]. Iulian Gherasim, Matthew Taws, Nicolas Galanis, Cong Tam Nguyen (2011), Heat transfer and fluid flow in a plate heat exchanger part-1: Experimental investigation, International Journal of Thermal Sciences 50:1492-1498.

[5] Goldstein. L. Jr.,Sparrow E.M. Heat mass transfercharacteristics for flow in corrugated channel:

Trans: ASME Heat transfer,(1977), 99,187-195.

[6] Lin. J.H., Huang. C.Y., C.C. Su, Dimensional Analysis For The Heat Transfer Characteristics In The Corrugated Channels of Plate Heat Exchangers: International Communications in Heat and Mass Transfer, (2007), Vol. 34, pp 304-312.

\section{BIOGRAPHIES}

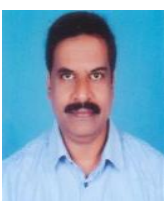

B. Sreedhara Rao is working as $\mathrm{Sr}$ Asst Professor in Chemical Engineering department of CBIT Hyderabad India.

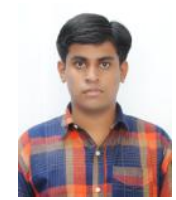

Varun S is a student of Master of Technology in department of Chemical Engineering at NIT Warangal India.

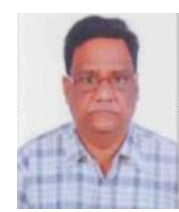

MVS Murali Krishna is working as Professor in Mechanical Engineering department of CBIT Hyderabad India.

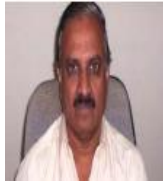

R. C. Sastry has joined the Department of Chemical Engineering, NIT Warangal (earlier REC) as Lecturer in the year 1979,promoted as Asst.Professor in the year 1992 and then as Professor in the year 1997. He worked as the Head of the Department for a period of 5 years from 2001 to 2006. 